\title{
Thermal Balance in the Process of Fresh Water Production from Atmospheric Air Using the Sea Waves Renewable Energy
}

\author{
Victor Mironov", Yuriy Ivanyushin ${ }^{1, *}$, Evgeniy Zhernakov ${ }^{1}$, and Dmitriy Mironov ${ }^{2}$ \\ ${ }^{1}$ Industrial University of Tyumen, Department of Water Supply and Sewerage, 625001 \\ Lunacharskogo str., 2, Russia \\ ${ }^{2}$ LLC “ELECTRORAM", Production Department, 652023 Przewalskogo str., 33/1, ap.79, Russia
}

\begin{abstract}
Climatic changes and man-induced environmental load cause to a shortage of drinking quality fresh water. Upon that, fresh water sufficiency is one of the preconditions for quality assurance in adequate living standards as well as for domestic and foreign political stability especially in developing countries. A lot of technologies of fresh drinking water production are known today. Most of them involve significant power consumption and endanger to environment. As a rule these technologies use non-renewable hydrocarbons as power source. The author-developed technology of fresh drinking water obtaining from atmospheric air involves the use of clean renewable energy of the sea. This article bases the method of water production from the air. It is also describes technology implementation energy balance.
\end{abstract}

\section{Introduction}

Only 2.5-3.0 percent of all available water on our planet is fresh, the minor part of this amount of fresh water is accessible for use by man. And not nearly all accessible fresh water has drinking quality. The problem of drinking quality fresh water supply is serious enough today for humankind. In background of this problem are several factors, including Earth population growth, maldistribution of water resources on our planet, climatic changes etc. [1].

There are a lot of engineering decisions of this problem today. Different common methods of sea water desalination are known, including distillation and reverse osmosis [2, 3]. But reverse osmosis has significant drawback consisting in necessity of periodic replacement of reverse osmosis membranes which are expendables. Distillation requires essential consumption of energy that supplied by combustion of nonrenewable hydrocarbons $[4,5]$. The majority of common methods of sea water desalination are developed to get high output of fresh water, more than 20 cubic meters per hour. At the same time in many instances it is necessary to have low-demand water desalinating plants (less than 200 liters per hour) or medium output plants (less than 200 cubic meters per hour) [6].

\footnotetext{
*Corresponding author: ivanyushin_yuriy@,mail.ru
} 
Obtaining of the fresh water from atmospheric sea air by condensation could also be referred to the technology of sea water desalination with low or medium fresh water output which doesn't have disadvantages described above [7]. Physical and chemical characteristics of condensate are very high. Such product contains less toxic metals, with little to no contains the bacteriological contamination and it is characterized by low content of deuterium affecting the human livelihood [8]. However, existing condensation technologies based on natural condensation have very low fresh water output. Forced-feed condensation while using existing technologies leads to extra power consumption. This article presents the technology of fresh water production from the atmospheric air by means of condensation using renewable ecologically harmless sea wave energy.

\section{Technology description}

To obtain the atmospheric condensate we propose to use modular units (see Fig. 1). For condensate production by using such units several technical solutions have been developed. They differ in degree of constructive complexity and energy efficiency. In all cases modular plants operating principle is based on forced saturation of atmospheric air with moisture due to heated sea water evaporation, moisture transfer in consequence of dew-point temperature rising under excess pressure and because of deposition of moisture in cold condenser [9, 10].
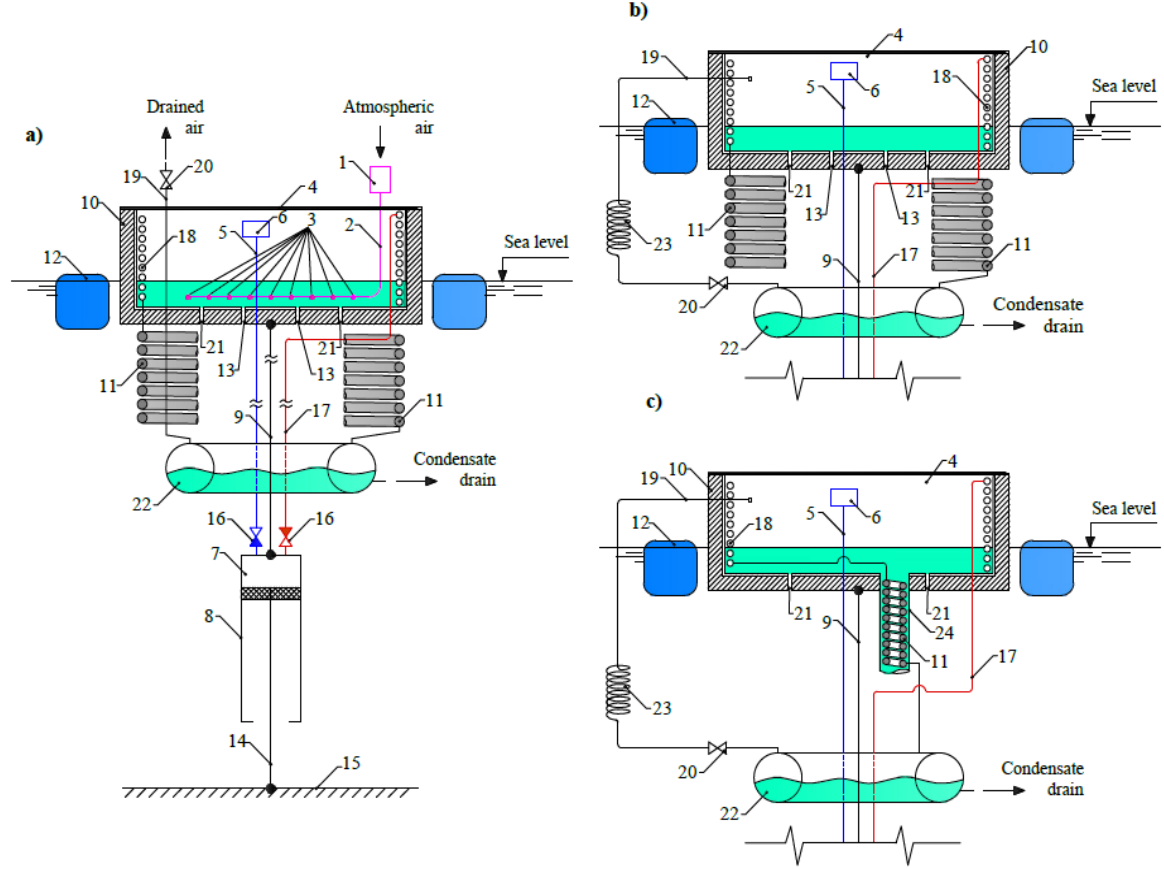

Fig. 1. Condensing unit principle diagram.

a) open cycle operation; b) closed-loop cycle operation using low-grade heat of sea water; c) closedloop cycle operation with condensation heat recuperation for the sea water feeding and heating. 1 - atmospheric air suction inlet; 2 - primary intake line; 3 - bubblers; 4 - internal vessel of the buoy; 5 - intake line; 6 - moisture saturated air receiving device; 7 - compression chamber; 8 - compressed air generator body; 9 - rope; 10 - buoy body; 11 - coiled tubular condenser; 12 - floater to provide buoy positive buoyancy; 13 - inlet hole for the sea water inflow; 14 - compression chamber piston plunger; 15 - sea floor surface; 16 - back pressure valves; 17 - pressure line; 18 - heat exchanger; 19 - dehumidified air discharge; 20 - throttle (expansion valve); 21 - sea water inlet and discharge holes; 22 - storage tank; 23 - low-grade heat exchanger; 24 - water intake pipe. 
Relative humidity of sea atmospheric air varies in a wide range depending on climatic and geographical conditions. In the modular unit (see Fig. 1, a) natural humidity of outside atmospheric air enters through the suction inlet (1) and primary intake line into the internal vessel of the buoy (4) which is situated inside the buoy (10). Further, the air bubbles through the heated sea water inside the buoy (10). Therefore, air becomes heated and saturated with vapour. In the inner tank of the buoy (4) sea water and air are heated by recovered heat released when air is compressed in the chambers (7).

Sea wave energy converter is a compressed air generator $(7,8)$ which is a compression chamber of piston compressor. The movable part of the compression chambers (7) is connected by ropes (9) with floating part of the plant, including the buoy (10) and coiled tubular condenser under sea level (11). If it is necessary the unit may optionally include a float with positive buoyancy (12). Inside the internal reservoir of the buoy (4) the helical heat exchanger (18) is mounted. The piston plunger (14) is rigidly fixed with sea bottom (15), by means of anchors or dead weight with negative buoyancy. Reciprocating motion of pistons in cylinders (8) is carried out by sea waves. During the air compression in the cylinders (8) its temperature increases.

To prevent reverse air flow, intake and pressure lines $(5,17)$ are equipped with back pressure valves (16). The compressed air in the pressure line (17) is sequentially fed first into the heat exchanger (18) located in the internal capacity of the buoy (4), and then to the condenser (11). Heat exchanger (18) heats the sea water and air in the reservoir (4) of the buoy (10). Specific humidity of the air sucked in by compressor (8) increases. The moisture contained in the air is condensed in the heat exchanger (18) and in the condenser (11) in a ratio determined by pressure and temperature ratings of the air inside the unit.

To minimize thermal losses of the body of the piston compressor (8), the pressure line (17) and the inner surface of the buoy internal vessel (4) are covered with thermal insulation. Condensation of moisture from the air happens on inner walls of the heat exchanger (18) and condenser (11). The condensate is collected in cumulative storage tank (22). Exhausting of dehumidified air is emitted into the atmosphere through the throttle (20) via line (19). For the open cycle operation (see Fig. 1a) dehumidified air exhausts into the atmosphere. For the scheme of closed-loop cycle operation, (see Fig. 1 b, c) we arranged air exhaust into the internal vessel of the buoy. This helps to prepare better quality air, which does not need extra filtering.

During the cold period, the temperature of dried exhausted air is higher than the temperature of outside air because of using less heated sea water in the closed-loop cycle. As a result decreases the energy needs for the air heating and its moisture saturation inside the buoy vessel. Transfer of the outside seawater heat goes on in the heat exchanger (21).

Closed-loop cycle operation effectiveness could be improved by using of heat recovery (see Fig. 1, c) generated in the tubular condenser (11) during moisture condensation. Condenser (11) and water intake pipe (24) together are the heat interchange apparatus provided for heating and feeding of the sea water to the internal vessel of the buoy (4).

Dimensions of the heat exchanger (18) as well as mass of the air inside are chosen to provide heat transfer of compressed air to the vessel of the buoy (4) in conditions of almost constant agent temperature during the cycle.

\section{Thermal balance modules}

Let's analyze the process of fresh water (condensate) obtaining from moisturized sea air using described technology as an example of closed-loop cycle (see schematic b). In principle, ignoring heat losses in modules, the energy balance for the operation cycle has to be written as: 


$$
E_{p}+Q_{\text {con }}^{1}=Q_{\text {air }}+Q_{\text {water }}+Q_{\text {evo }},
$$

where: $E_{p}$ is the energy given to the agent (air) during compression, $J ; Q^{1}$ con - steam condensation heat, while condensate dropout on inner walls of the heat exchanger (18), J; $\mathrm{Q}_{\text {air }}$ - heat input necessary for dried air inlet warming, J; $\mathrm{Q}_{\mathrm{evo}}$ - heat absorbed while seawater evaporation inside the buoy, $\mathrm{J} ; \mathrm{Q}_{\text {water }}$ - heat input necessary for warming of the water coming into the buoy internal vessel (4) instead of condensated, J.

The left side of the energy balance equation shows the energy given to the agent (air), the right side of the equation includes all of the energy input. For a first approximation moisture saturated air compression process could be concerned as adiabatic. Adiabatic air compression is described by formula $[11,12]$ :

$$
E_{p}=\frac{k}{k-1} \cdot p_{\text {atm }} \cdot V_{\text {com }} \cdot\left[\left(\frac{p_{\text {fin }}}{p_{\text {atm }}}\right)^{\frac{k-1}{k}}-1\right],
$$

where: $k$ is air isentropic volume exponent; $p_{a t m}$-absolute initial (atmospheric) pressure, Pa; $V_{\text {com }}$ - compression chamber volume, $\mathrm{m}^{3} ; p_{f i n}$ - absolute pressure after the compression, $\mathrm{Pa}$.

Air temperature potential increases during the compression process because the air receives the quantity of heat $Q_{p}$, whilst $Q_{p}=E_{p}$ :

$$
Q_{p}=c_{\text {air }} \cdot M_{w a} \cdot\left(T_{2}-T_{1}\right),
$$

where: $T_{1}$ - is steady temperature in buoy internal vessel (temperature of moisturized air induced to the compression chamber), $\mathrm{K}$; $c_{\text {air }}$ - mean specific heat of the air, $\mathrm{J} / \mathrm{kg} \cdot \mathrm{K}$, in a range of changes of operational temperatures and pressures; $M_{w a}$ - moisture saturated air mass, $\mathrm{kg} ; T_{2}-$ after compression temperature, $\mathrm{K}$ :

$$
T_{2}=\left(\frac{p_{f i n}}{p_{a t m}}\right)^{\frac{k-1}{k}} \cdot T_{1} ;
$$

The pressure developed by compression chambers:

$$
p_{\text {fin }}=p_{\text {atm }}+p_{h s}=p_{a t m}+\rho \cdot g \cdot H,
$$

where: $p_{h s}$ is hydrostatic pressure of water layer above compression chamber, Pa; $\rho$ - sea water density, $\mathrm{kg} / \mathrm{m}^{3} ; \mathrm{g}$ - gravity factor, $\mathrm{m} / \mathrm{s}^{2} ; H$ - compression chamber immersion depth, $\mathrm{m}$.

Compression chamber volume based on specifications:

$$
V_{\text {com }}=\frac{\pi \cdot D_{c}}{4} \cdot h,
$$

where: $D_{c}$ - compression chamber cylindrical cavity diameter, $\mathrm{m} ; h$ - compression chamber operating run corresponded with sea wave height, $\mathrm{m}$.

While units are in operation, the moisturized air could be in several states: in the buoy internal vessel at the temperature $T_{l}$ and absolute pressure $p_{a t m}$, in the condenser at the temperature $T_{1}$ and absolute pressure pfin, in atmosphere at the temperature of outside air $T_{a}$ and absolute pressure $p_{a t m}$, (to be considered in open cycle design calculation).

Moisturized air should be regarded as a mix of following separate components: dried air and steam. In this case moisturized air density could be determined relying on partial pressure by known formula [13]:

$$
\rho_{\text {wa }}=\frac{\varphi \cdot p_{1} \cdot \mu_{\text {water }}+\left(p_{\text {atm }}-\varphi \cdot p_{1}\right) \cdot \mu_{\text {air }}}{R_{0} \cdot T_{1}},
$$

where: $\varphi$ is relative humidity of the air in the buoy internal vessel; $\mu_{\text {water }}$ - molar weight of the steam (water), $\mathrm{kg} / \mathrm{mole} ; \mu_{\text {air }}$ - air molar weight, $\mathrm{kg} / \mathrm{mole} ; R_{0}$ - universal gas constant, $\mathrm{J} /($ mole $\cdot \mathrm{K}) ; p_{1}-$ steam partial pressure, calculated by [14]: 


$$
p_{1}=\left(1.0016+\frac{3.15 \cdot p_{a t m}}{10^{8}}-\frac{7.4}{p_{\text {atm }}}\right) \cdot 611.2 \cdot e^{\frac{17.62 \cdot T_{1}^{C}}{243.12+T_{1}^{C}}}
$$

where: $T_{l}{ }^{C}$ is the temperature in the buoy internal vessel, degrees Celsius, ${ }^{\circ} \mathrm{C}$.

Relation (7) allows getting moisturized air density values with sufficient degree of precision in the range if temperatures from $0^{\circ} \mathrm{C}$ to $100^{\circ} \mathrm{C}$. So the weight of moisturized air and its components in an enclosed volume $V_{\text {com }}$ are equal:

$$
\begin{aligned}
M_{w a} & =\rho_{w a} \cdot V_{c o m} ; \\
M_{\text {water }} & =\rho_{\text {water }} \cdot V_{c o m} ; \\
M_{\text {air }} & =\rho_{\text {air }} \cdot V_{c o m} .
\end{aligned}
$$

where: $\rho_{\text {water }}-$ steam density, $\mathrm{kg} / \mathrm{m}^{3} ; \rho_{\text {air }}-$ dry air density, $\mathrm{kg} / \mathrm{m}^{3}$.

Densities, weights and volumes (if necessary) of inlet moist air and its components are calculated using formulas (6-10).

Energy consumption for heating of sea water coming into the reservoir (4) instead of condensed $Q_{\text {water }}$, J, is:

$$
Q_{\text {water }}=c_{\text {water }} \cdot M \cdot\left(T_{1}-T_{w}\right),
$$

where: $c_{\text {water }}$ is inlet sea water heat capacity, $\mathrm{J} /(\mathrm{kg} \cdot \mathrm{K}) ; T_{w}$ - outside sea water temperature, equal to the air temperature achieved in condenser, $\mathrm{K} ; M$ - weight of the condensated moisture assumed equal to the weight of sea water coming into the vessel (4), $\mathrm{kg}$ :

$$
M=M_{\text {water }}-M_{\text {res }},
$$

where: $M_{\text {water }}$ is weight of water contained in the moist air sucked into compression chambers, $\mathrm{kg} ; M_{\text {res }}$ - residual content of moisture in the air after condenser at the temperature $T_{w}$ and absolute pressure $p_{\text {fin }}$.

Heat energy absorbed during water evaporation in the buoy internal vessel $Q_{e v o}$, J, is:

$$
Q_{\text {evo }}=c_{\text {evo }} \cdot M \text {, }
$$

where: $c_{\text {evo }}$ is specific heat of evaporation, $\mathrm{J} / \mathrm{kg}$.

Energy consumption for heating of inlet dry and expanded air $Q_{\text {air }}, \mathrm{J}$, is:

$$
Q_{\text {air }}=\left[c_{\text {air }} \cdot M_{\text {air }}+c_{\text {water }} \cdot M_{\text {res }}\right] \cdot\left(T_{1}-T_{w}\right),
$$

where: $c_{a i r}$ is dry air heat capacity, $\mathrm{J} /(\mathrm{kg} \cdot \mathrm{K})$.

Moisture condenses in the coiled tubular condenser (11) and condenser (18). So all condensed moisture could be shown as a sum:

$$
M=M_{h e x}+M_{c o n},
$$

where: $M_{h e x}$ is the weight of water condensed during air movement in the heat exchanger (18), $\mathrm{kg} ; M_{c o n}$ - the weight of water condensed during air movement in the coiled tubular condenser (11), $\mathrm{kg}$.

The amount of heat generated while moisture condensation in the buoy heat exchanger is:

$$
Q_{\text {con }}^{1}=c_{h e x} \cdot M_{h e x},
$$

where: $c_{\text {hex }}-$ condensation latent heat, $\mathrm{J} / \mathrm{kg}$.

On conversion to one kilogram of moisture saturated air thermal energy balance equation looks like:

$$
\frac{1}{M_{a}} \cdot\left[Q_{p}+Q_{c o n}^{1}\right]=\frac{1}{M_{a}} \cdot\left[Q_{\text {air }}+Q_{\text {water }}+Q_{\text {evo }}\right]
$$

For the open cycle (see schematic a) thermal energy balance equation looks similar to the formula (18). The only difference is in discharge of dry air into the atmosphere and inlet of the air from outside. In this case energy consumption for heating and evaporation of sea 
water could be less because inlet sea atmospheric air is initially enough saturated with moisture. So the weight of evaporated sea water $M$ is determined as:

$$
\begin{gathered}
M=M_{\text {water }}-M_{\text {water }}^{\text {out }}, \\
Q_{\text {con }}^{1}=c_{\text {hex }} \cdot M_{\text {hex }},
\end{gathered}
$$

where: $M_{\text {water }}^{\text {out }}$ is weight of the steam contained in atmospheric air, kg. It is determined using formulas (6-10) depending on outside air temperature $T_{\text {air }}$ and atmospheric pressure $p_{\text {atm }}$.

Energy input for heating of inlet atmospheric air $Q_{\text {air }}$ in case of operating in the open thermodynamic cycle during the worm period is also should be decreased because of the heat is needed from higher temperature $T_{\text {air }}$ to $T_{1}$ :

$$
Q_{\text {air }}=\left[c_{\text {air }} \cdot M_{\text {air }}+c_{\text {water }} \cdot M_{\text {water }}^{\text {out }}\right] \cdot\left(T_{1}-T_{\text {ait }}\right) \text {. }
$$

Application of thermal energy balance equation (18) allows to design the plants for fresh water obtaining with specific parameters and characteristics actual for the place of their installation. Such parameters are: compression chambers immersion depth $H(\mathrm{~m})$, ambient sea water temperature $T_{w}(\mathrm{~K})$, outside air temperature $T_{\text {air }}(\mathrm{K})$ and humidity $\varphi(\%)$ - for the case of open cycle. Thermal energy balance equation for the closed-loop cycle considering recuperation of the condensation heat for sea water feeding and heating could be written separately for the buoy internal vessel (4) and the heat exchanger (see Fig. 1, c, reference numbers 11 and 24).Thermal energy balance is composed according to the condition that the heat $Q_{p}$ given to the air while compressing and condensation heat $Q^{I}$ con generated in the heat exchanger while condensation are used only for sea water evaporation inside the buoy vessel and for heating of inlet dry air.

Heating of sea water inflowing to the buoy vessel is made by condensation heat $\mathrm{Q}^{2}$ con generated in the condenser and also by the heat flow $Q_{l-w}$ characterizing cooling of compressed air heated from water. On the basis of worded thermal energy balance equations for the schematic $c$ look:

- for the buoy internal vessel:

$$
\frac{1}{M_{a}} \cdot\left[Q_{p}+Q_{c o n}^{1}\right]=\frac{1}{M_{a}} \cdot\left[Q_{\text {air }}+Q_{\text {evo }}\right]
$$

- for the condenser:

$$
\frac{1}{M_{a}} \cdot\left[Q_{c o n}^{2}+Q_{1-w}\right]=\frac{1}{M_{a}} \cdot Q_{\text {water }} .
$$

Amount of heat generated in condenser:

$$
Q_{\text {con }}^{2}=c_{c o n} \cdot M_{c o n},
$$

where: $c_{c o n}-$ is condensation latent heat at average air temperature in the condenser and absolute pressure $p_{\text {fin }}, \mathrm{J} / \mathrm{kg}$.

The heat characterizing cooling of compressed air during water heating:

$$
Q_{1-w}=\left[c_{\text {air }} \cdot M_{\text {air }}+c_{\text {water }} \cdot\left(M_{\text {res }}+M_{\text {con }}\right)\right] \cdot\left(T_{1}-T_{w}\right),
$$

or relatively heating water

$$
Q_{\text {water }}=c_{\text {water }} \cdot M_{f} \cdot\left(T_{1}-T_{w}\right),
$$

where: $M_{f}$ - weight of inflow water supplied to intake pipe, $\mathrm{kg}$.

It stands to mention that weight of water, which is heating $M_{f}$ and weight of water, which is evaporating from surface in the buoy $M$ are not equal. The difference $\Delta M=M_{f}-M$ is value circulating in the buoy internal vessel constantly. Water flow quantity relevant to the weight $\Delta M$ is intended for regular water renew as far as water salt content will be rising while operation of the plant. 


\section{Results}

Compression chambers immersion depth is major characteristic that has influence on technology output rate. With the use of equations mentioned above $(18,22,23)$ characteristic curves were plotted (see fig. 2-4). These curves demonstrate dependency relation of condensed water weight (normalized to dry air unit of mass) on compression chambers immersion depth. Calculation considers that water temperature in the buoy internal vessel corresponds to the moist air temperature $T_{l}$. Upper limit of the temperature $T_{l}$ is set to $70^{\circ} \mathrm{C}$. Increasing of the set temperature level in the buoy internal vessel leads to salting, precipitated hardness and finally to plant operational faults. Numeric computation has shown that compression chambers immersion depth of 40 meters or more provides generating of compressed air energy as much as necessary to achieve the temperature in the buoy internal vessel (4) more than $100{ }^{\circ} \mathrm{C}$. So the water starts to boil with fast growth of the plant fresh water output and with rapid limescale buildup [15]. For example amount of limescale appeared at water temperature of $80^{\circ} \mathrm{C}$ is seven times exceeds of its amount appeared after heating the water to a temperature of $60^{\circ} \mathrm{C}$. Such operation mode of the plant is not inadmissible.

Compression chambers immersion depth is the major characteristic that has influence on technology output rate. With the use of equations mentioned above $(18,22$, and 23) characteristic curves were plotted (see fig. 2-4). These curves demonstrate dependency of relation of condensed water weight (normalized to dry air unit of mass) on compression chambers immersion depth. Calculation considers that water temperature in the buoy internal vessel corresponds to the moist air temperature $T_{l}$. Upper limit of the temperature $T_{l}$ is set to $70^{\circ} \mathrm{C}$. Increasing of the set temperature level in the buoy internal vessel leads to salting, precipitated hardness and finally to plant operational faults. Numeric computation has shown that compression chambers immersion depth of 40 meters or more provides generating of compressed air energy as much as necessary to achieve the temperature in the buoy internal vessel (4) more than $100^{\circ} \mathrm{C}$. So the water starts to boil with fast growth of fresh water output and with rapid limescale buildup [15]. For example amount of limescale appeared at water temperature of $80^{\circ} \mathrm{C}$ is seven times exceeds of its amount appeared after heating the water to a temperature of $60^{\circ} \mathrm{C}$. Such operation mode of the plant is not inadmissible.
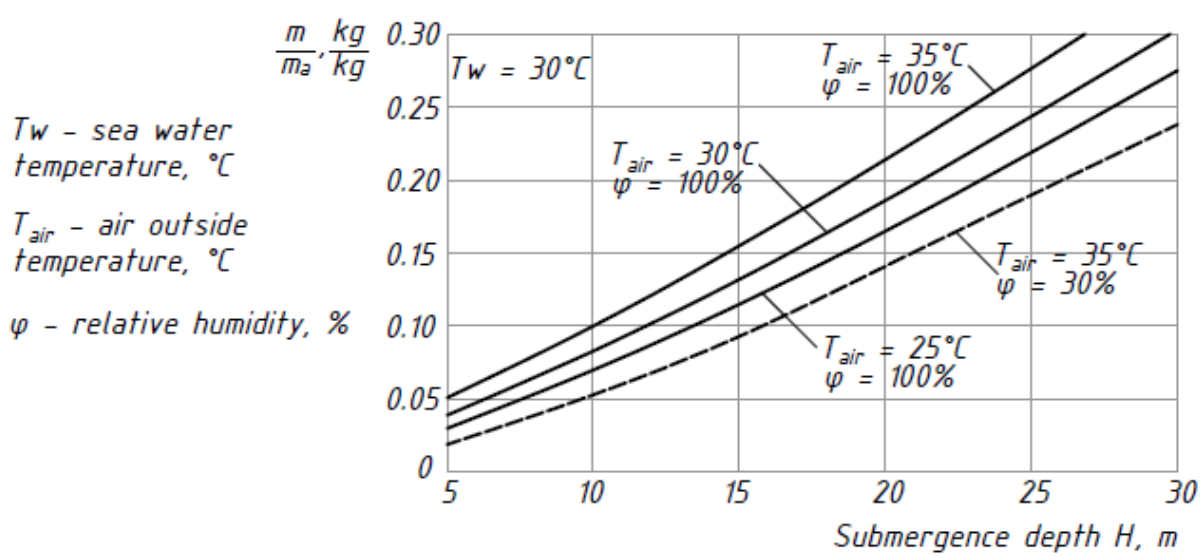

Fig. 2. Weight of the water condensed from one kilogram of air at different temperatures of outside air as a function of compression chambers immersion depth during open cycle. 


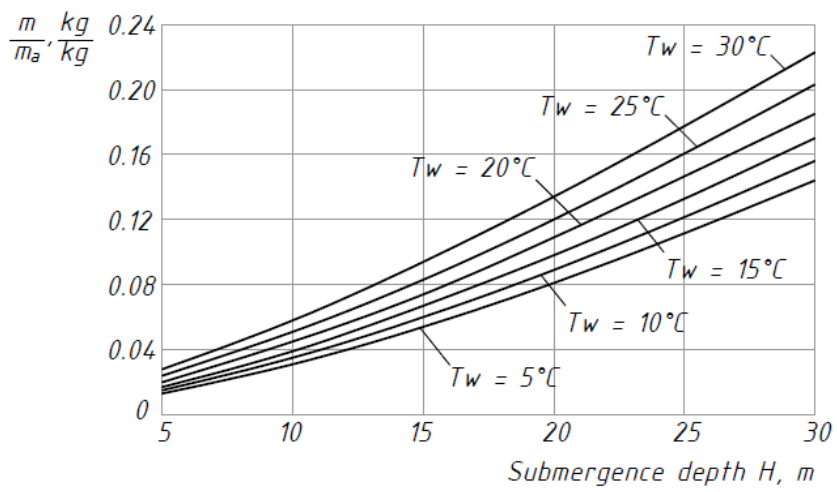

Fig. 3. Weight of the water condensed from one kilogram of air at different temperatures of outside air as a function of compression chambers immersion depth during the closed-loop operation cycle using low-grade heat of sea water.

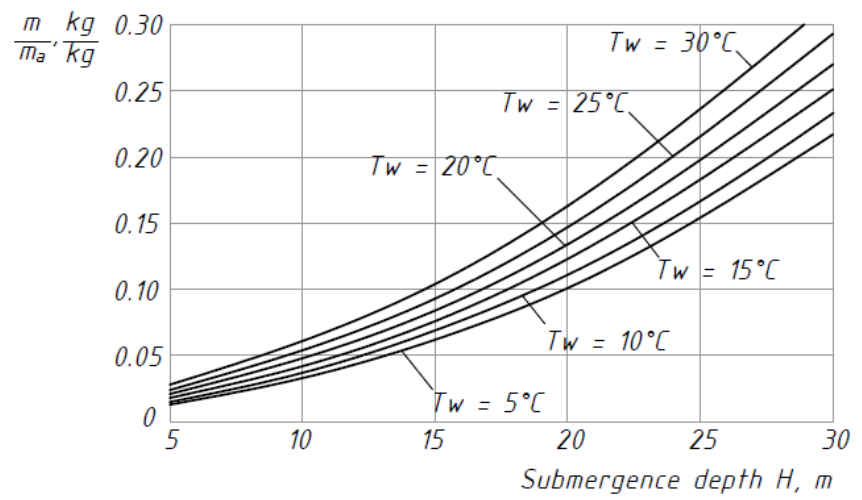

Fig. 4. Weight of the water condensed from one kilogram of air at different temperatures of outside air as a function of compression chambers immersion depth during the closed-loop operation cycle with condensation heat recuperation for the sea water feeding and heating.

To determine actual modular plant output it is required to consider cyclicity of operation mode that depends on wave period. The mass of condensed moisture determined with the use of the thermal balance equations $(18,22$ and 23) or by its graphic representation (see Fig. 24 ) recalculated to operation cycle. So condenser unit output per hour should be determined as:

$$
M_{h r}=\frac{3600}{t} \cdot\left(\left[\frac{m}{m_{a}}\right] \cdot M_{a}\right),
$$

where: $t$ is averaged sea wave period, $\mathrm{s} ;\left[\mathrm{m} / \mathrm{m}_{\mathrm{a}}\right]$ - obtained fresh water mass, normalized to one kilogram of the air, $\mathrm{kg} / \mathrm{kg}$.

\section{Conclusions}

The analysis of modular unit operation for obtaining of clean fresh water from moisture saturated atmospheric air revealed that exploitation of structurally simple open thermodynamic air cycle is effective in warm climatic conditions. In these conditions power consumption for the forced air saturation of moisture vapor is minimal. Closed-loop operation thermodynamic air cycle is more complicated constructively, but more effective for cold climate aquatorium. In closed cycle it is possible to use of lowgrade heat of ambient 
sea water and preliminary filtering of inlet atmospheric air is not necessary as it could be specified for open cycle.

Basing on thermal energy balance equations relative graphic functions were plotted to determine the amount of obtained condensed moisture from the unit of air mass depending on modular plant immersion depth and ambient temperature.

Developed functions allow to make calculations of modular plants for clean fresh water obtaining from the air forcibly saturated with moisture vapor by using the method of condensation powered by renewable energy of the sea wave.

\section{References}

1. V.A. Gorbachev, Water problem in the conditions of globalization, Mirovoe $\mathrm{i}$ natsional'noe khozyaystvo, 4, 9 (2016) (in Russian)

2. R. Bahar, M.N.A. Hawlader, Desalination: Conversion of Seawater to Freshwater, ICMAAE 2013, 1-5 (2013)

3. B.B. Tanganov, Sea water and the problem of its desalination, Sovremennye naukoemkie teknologii, 7, 90-92 (2010) (in Russian)

4. V.V. Biryuk et al, The method of evaluation of the efficiency of distillation desalination plants, Uspekhi sovremennoi nauki, 12, 188-193 (2016)

5. M.K. Wittholz, B.K. O'Neill, C.B. Colby, D. Lewis, Estimating the cost of desalination plants using a cost database, Desalination, 229, 10-20 (2008)

6. URL: http://tgm-pumps.ru/Biosphere/Opresnenie_ABP.html (in Rissian)

7. A. Magrini, M. Cattani, M. Cartesegna, L. Magnani, Production of Water from the Air: The Environmental Sustainability of Air-conditioning Systems through a More Intelligent Use of Resources. The Advantages of an Integrated System, Energy Procedia, 78, 1153-1158 (2015)

8. T. Strekalova et al, Behavioural Brain Research, 277, 237-244 (2015)

9. Patent RU 2609375 Method of obtaining water from the air, V.V. Mironov, D. V. Mironov, Yu.A. Ivanyushin, I.V. Yakimova, 4, (2017)

10. K. Rajasekar et al, Effect on air quality and flow rate of fresh water production in humidification and dehumidification system, 2017 IOP Conf. Ser.: Mater. Sci. Eng. 183 012032 (2017)

11. S.M. Altuhov, V.A. Rumyantsev, Diaphragm comressors, 128, (1967) (in Russian)

12. S.L. Dixon, C. Hall, Fluid Mechanics and Thermodynamics of Turbomachinery: 7th Edition (Elsevier Inc., 537, 2013)

13. R. Shelquist, An Introduction to Air Density and Density Altitude Calculations (2009), URL: https://wahiduddin.net/calc/density_altitude.htm

14. Guide to Meteorological Instruments and Methods of Observation (WMO-No. 8), 2008 URL: https://library.wmo.int/pmb_ged/wmo_8_en-2012.pdf

15. H. Hillier, O.B.E., Scale Formation in Sea-Water Distilling Plants and its Prevention, Proc. of the I Mech E, Part B: J. of Eng. Man., 1, 295-322 (1953) 